\title{
Attachment and spousal caregiving
}

\author{
JUDITH A. FEENEY ${ }^{a}$ AND LYDIA HOHAUS ${ }^{b}$ \\ ${ }^{a}$ School of Psychology, University of Queensland; and ${ }^{b}$ School of Applied Psychology, \\ Griffith University
}

\begin{abstract}
A community sample of 362 married couples participated in a study of attachment and spousal caregiving, which combined qualitative and quantitative components. The qualitative component focused on actual experiences of caregiving, assessed by participants' semi-structured accounts of a situation involving their role as caregiver for their spouse. Attachment styles and their underlying dimensions (comfort with closeness, anxiety over relationships) were related to the type of support provided, the coping strategies used in the situation, caregivers' feelings about the quality of their care, perceived effects on the couple bond, and the emotional tone of the accounts. The quantitative component tested a theoretical model of factors predicting willingness to provide care for the spouse if he or she should become dependent in later life. Measures of attachment and caregiving styles, attachment to spouse, and anticipated burden provided reliable prediction of willingness to care. The results support the conceptualization of attachment and caregiving as interrelated features of marital bonds, and they have important implications for patterns of family caregiving.
\end{abstract}

Family caregiving in later life is rapidly becoming a critical social and community issue. Several interrelated reasons account for this development (Marks, 1998). First, because of increased longevity, elderly people are requiring relatively prolonged periods of caregiving. Second, there is likely to be a steady increase in the proportion of seniors within Western societies in the twenty first century; hence, the proportion of individuals requiring such assistance will increase markedly. Third, in terms of resources for caregiving, it is likely that contributions from the public sector and other community sources will continue to decline. For these reasons, it is anticipated that more assistance will be provided by family caregivers in the future (Fredriksen, 1996).

When a frail elder requires caregiving from within the family, the spouse is the person most likely to provide that care (Brody, 1985; Stone, Cafferata, \& Sangl, 1987). Although caring for an impaired

Electronic mail may be sent to J.Feeney@psy.uq. edu.au. partner may be seen as an inherent part of the marriage contract, spouses vary in their willingness to provide care and in the degree of personal burden experienced as caregiver (Miller, McFall, \& Montgomery, 1991; Orbell, Hopkins, \& Gillies, 1993). These individual differences in responses to caregiving have vital implications for the well-being of both caregiver and receiver of the care and for decisions about institutional placement (McFall \& Miller, 1992; Mui, 1995).

The present study was designed to examine participants' actual experiences of spousal caregiving, and to test a theoretical model of factors influencing willingness to provide care for a dependent spouse in later life. The model was guided by recent developments in adult attachment theory.

\section{Romantic Love as Attachment}

Adult attachment theory is grounded in Bowlby's (1969, 1973, 1980) work, which showed the critical importance to individual development of the bond between child and caregiver. Consistent with Bowlby's 
claim that the attachment system plays a crucial role across the life span, researchers have argued that some adult relationships (particularly marriage, and other committed love relationships) are attachment bonds. Spouses seek closeness to their partners, experience distress if they become unavailable, derive a sense of security from their relationships, and turn to partners for comfort in times of stress. These behaviors are similar to the defining features of attachments, involving proximity seeking, separation protest, secure base, and safe haven (Ainsworth, 1989; Weiss, 1991).

Hazan and Shaver's (1987) seminal studies supported the conceptualization of romantic love as attachment. In these studies, a simple categorical measure of attachment style (secure, avoidant, anxious-ambivalent) was related to reports of early family relations, beliefs about romantic love, and the quality of love experiences. Other measures of adult attachment style have since been developed. Some are based on a four-group typology (Bartholomew, 1990; Bartholomew \& Horowitz, 1991), which identifies attachment styles labeled secure, preoccupied (cf. anxious-ambivalent), dismissing-avoidant (marked by the downplaying of close relationships), and fearfulavoidant (characterized by distrust and fear of rejection). Multiple-item measures have also been developed that tap two major dimensions: comfort with closeness and anxiety over relationships (Feeney \& Noller, 1996). These scales may be more sensitive to individual differences than are categorical measures (Feeney, 1995).

Regardless of the measures used, a large body of research attests to the importance of individual differences in adult attachment style as a predictor of processes and outcomes in couple relationships. Secure individuals report less conflict, greater acceptance of their partners, more interdependence, more constructive ways of coping with stress, and more satisfying and stable relationships (see Feeney \& Noller, 1996, for a review). There is also evidence of the discriminant validity of the different insecure styles; for example, those high in rela- tionship anxiety (cf. anxious-ambivalence) show particularly high levels of conflict in their relationships (Feeney, Noller, \& Roberts, 2000).

Other research suggests that individuals differ not only in attachment style, but also in attachment strength; that is, the extent to which particular people are relied on for a sense of comfort and security. Hazan and Zeifman (1994) interviewed children and adults to assess their reliance on various attachment figures (parents, friends, and romantic partners). As individuals established long-term romantic relationships, their reliance on romantic partners as attachment figures increased. Fraley and Davis (1997) adapted this interview measure to produce questionnaire items assessing the strength of reliance on particular attachment figures. Even when attachment style was statistically controlled, stronger attachment to romantic partners was associated with higher scores on relationship variables such as trust and mutual support. This finding suggests that attachment style and attachment strength are separable constructs, both of which influence relationship quality.

\section{Attachment and caregiving in marriage}

As well as their empirical studies, Shaver and Hazan (1988; Shaver, Hazan, \& Bradshaw, 1988) presented a theoretical analysis of love as attachment, noting two clear differences between romantic love and infant attachment. First, romantic love (unlike infant attachment) has a sexual component. Second, romantic love typically involves reciprocal caregiving; in contrast, infantcaregiver bonds have highly asymmetrical patterns of caregiving, as the term caregiver implies. These points led Shaver and Hazan to argue that romantic love involves the integration of attachment, caregiving, and sexuality. This model fits with Bowlby's (1973) work, which described attachment, caregiving, and sexual mating as organized systems of behavior that work together to ensure the survival of the species. Attachment has a central role in this model: It is the first system to appear in the course of 
development, and hence it influences the expression of the others. Further, although sexual attraction is often very important in the early stages of a relationship, attachment and caregiving are likely to become relatively more important as the relationship persists, and to sustain the bond when sexual interest wanes (Ainsworth, 1989).

The link between adult attachment and caregiving was first studied by Kunce and Shaver (1994), who developed self-report scales (proximity, sensitivity, cooperation, and compulsive caregiving) to assess the quality of caregiving in romantic dyads. In a student sample, these scales differentiated attachment groups in ways consistent with attachment theory. For example, preoccupied and fearful participants reported more compulsive caregiving than did secure and dismissing participants. Secure and preoccupied participants reported high levels of proximity (physical and psychological), but only secure participants reported being highly sensitive to partners' needs and signals. Scores on the scales were stable over a 1 -month period, and their validity as measures of caregiving behavior was supported by data from young couples, showing reliable correlations between self-reports and partner reports of both men's and women's caregiving (Kunce \& Shaver, 1994).

The link between attachment and caregiving is supported by subsequent research. In a broad sample of married couples who completed Kunce and Shaver's measure, secure attachment was related to constructive caregiving (Feeney, 1996). That is, comfort with closeness was related negatively to compulsive care and positively to responsive care (a composite of proximity, sensitivity, and cooperation); anxiety over relationships showed the reverse pattern of relations. In terms of attachment groups, secure participants reported the most constructive caregiving (low compulsive, high responsive); fearful participants reported the least constructive. Marital satisfaction was predicted by secure attachment and by partner's responsive care. Similarly, in a study of dating and married couples, secure attachment was related to a measure of beneficial care, and relationship satisfaction was predicted by attachment and caregiving styles (Carnelley, Pietromonaco, \& Jaffe, 1996).

\section{The Present Study}

This study was designed to replicate and extend research linking attachment style with patterns of spousal caregiving. (Attachment theory has been applied to the caregiving context by Cicirelli [1993, 1995], but that research has focused on filial caregiving, and has not studied individual differences in attachment style.) Specifically, the present study has a number of important features that extend the research conducted by Kunce and Shaver (1994).

First, the study involved a large sample of couples who varied widely in terms of variables such as age, education, and occupation; this feature is important in terms of the generality of the findings. Second, it focused specifically on marital bonds; given the commited nature of such bonds, experiences and expectations of caregiving are likely to be even more salient than in dating relationships. Third, both attachment style and strength of attachment to spouse were measured, to clarify the implications of these two constructs for spousal caregiving. Fourth, whereas Kunce and Shaver's measure focuses implicitly on responses to typical problems and stressors, the present study investigated caregiving under more stressful conditions (the time in the marriage when care was most needed, and requirements for long-term care in the future). Fifth, the study integrated attachment and caregiving with burden, a key variable in the literature on elder caregiving. Finally, the study combined measures of past, current, and future caregiving, using both qualitative and quantitative methods. Any single approach to this topic has limitations (e.g., retrospective reports may be prone to memory biases), but by combining approaches, caregiving attitudes and behaviors can be assessed as fully as possible. In particular, assessment of willingness to care in the future is a novel feature of this study, 
and one with great practical significance. Research questions and hypotheses for each component of the study are presented below.

\section{Qualitative component}

The qualitative component of the study focused on actual experiences of caregiving. To capture these experiences as fully as possible, participants were asked to provide semi-structured accounts of a situation involving their own role as caregiver for their spouse. Content coding was used to assess the type of support provided, how the caregiver had coped, how the situation had affected the marriage, and how the caregiver felt about the care he or she had provided. The emotional tone of the accounts was also assessed, focusing on whether respondents were accepting or rejecting of spouses' needs.

Secure attachment was expected to be linked to reports of effective care. Specifically, Hypothesis 1 predicted that secure attachment (high comfort with closeness; low anxiety over relationships) would be related to provision of "complete" support (i.e., both tangible and emotional), to constructive coping (problem-focused; support-seeking), and to reports of positive effects on the relationship. Hypothesis 2 predicted that preoccupied and fearful attachment (high anxiety over relationships) would be related to a compulsive style of caregiving, marked by emotion-focused coping and dissatisfaction with care. According to Hypothesis 3, avoidant attachment (low comfort with closeness) should be inversely related to support-seeking; further, avoidant attachment (particularly dismissing attachment) should be linked with less acceptance of spouses' needs and behaviors, and hence with the use of a negative or hostile tone in describing these issues.

\section{Quantitative component}

The quantitative component involved the use of structured questionnaires, and it focused on predicting willingness to care for the spouse if he or she should become dependent in later life. Figure 1 presents the model guiding this part of the research. In general terms, the model proposes that adult attachment style is related to patterns of caregiving. Further, these interrelated systems of behavior (attachment and caregiving) are associated with willingness to care. However, these associations may be explained, at least in part, by the anticipated burden linked with caregiving, and the strength of attachment to the spouse (that is, the degree to which the spouse is used to meet attachment needs).

More specifically, Figure 1 proposes that secure attachment should be related to constructive caregiving (more responsive care, less compulsive care; Hypothesis 4). Both

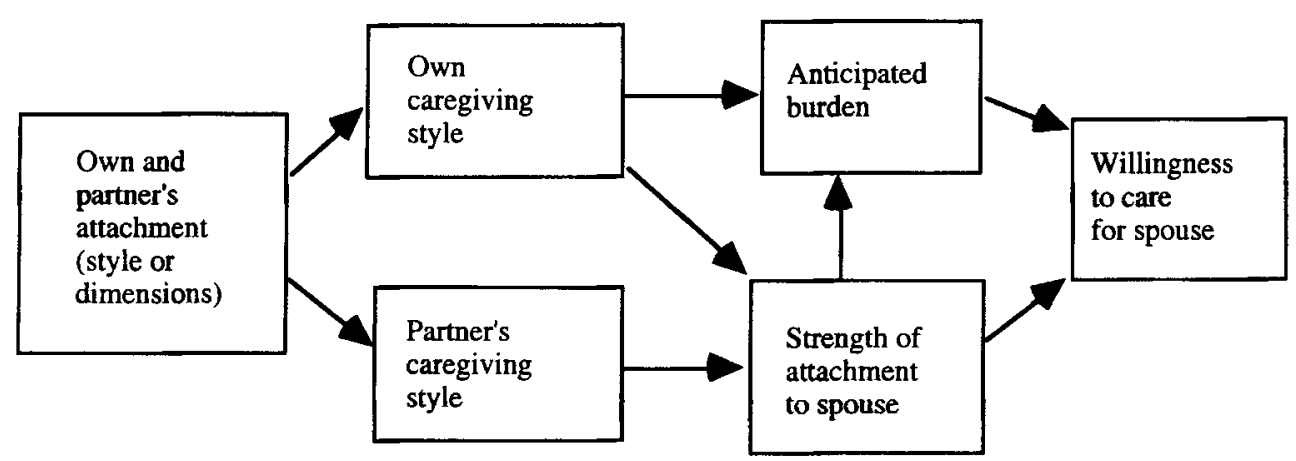

Figure 1. Theoretical model linking attachment and caregiving variables with willingness to provide care. 
secure attachment and constructive caregiving should be linked to willingness to care (Hypothesis 5); no prediction was made as to whether these associations would involve direct effects, or indirect effects through anticipated burden and strength of attachment. However, it was expected that willingness to care would be related negatively to burden and positively to attachment strength (Hypothesis 6). Note that attachment strength is conceptualized as influenced by styles of attachment and caregiving, as these styles are thought to play an active role in shaping partners' dayto-day interactions. However, an alternative model was also tested, which conceptualized all aspects of the attachment system (attachment style and attachment strength) as predictors of caregiving (caregiving styles, burden, and willingness to care).

\section{Method}

\section{Participants}

Participants were a community sample of 362 married couples. To participate, couples were required to have been married for at least 1 year, with the marriage being the first marriage for both partners, and to include at least one spouse between the ages of 21 and 55 years inclusive. Forty-four couples had one spouse who was enrolled in introductory psychology courses at the University of Queensland; the remaining couples were recruited by students in these courses. In either case, students involved in the study received course credit for their participation.

The sample was broadly based, although with some bias toward higher socioeconomic levels. Forty-four husbands and 70 wives had not completed high school, 156 husbands and 149 wives had completed high school, and 157 husbands and 142 wives had completed a tertiary degree. Thirty-two husbands and 103 wives were not engaged in paid work (being either students, homemakers, or unemployed), 79 husbands and 104 wives were employed in manual or clerical positions, and 251 hus- bands and 155 wives held managerial or professional positions. Ages ranged from 19 to 69 years for husbands ( $M=38.66$ years), and 18 to 60 years for wives $(M=36.29$ years). Length of marriage ranged from 1 to 34 years $(M=13.53$ years $)$. Sixty-nine percent of the sample had children.

\section{Materials}

Participants completed a questionnaire package measuring background information (gender, age, educational and occupational status, length of marriage, number of children), attachment style, caregiving style, attachment to spouse, anticipated burden, and willingness to care for spouse. Participants also answered a set of semi-structured questions concerning their actual experiences of caring for their spouse.

Attachment style. Two measures of attachment style were used (see Griffin \& Bartholomew, 1994). The Relationship Questionnaire presents brief descriptions of four attachment prototypes (secure, preoccupied, dismissing, fearful). Participants are asked to choose the prototype that best describes their feelings about close relationships, and to rate the applicability of each prototype, from 1 = not at all like me, to $7=$ very much like me. As recommended by Kunce and Shaver (1994), one phrase was omitted from the secure and dismissing descriptions to avoid overlap between measures of attachment and caregiving.

Participants also completed the 30 -item Relationship Scales Questionnaire, rated from $1=$ not at all like me, to $5=$ very much like me. Principal components factor analysis of the items, conducted on the full sample, yielded two orthogonal factors that explained $39.1 \%$ of the variance. Consistent with other studies of adult attachment, the factors measured comfort with closeness (referred to as comfort) and anxiety over relationships (referred to as anxiety). (Separate analyses for husbands and wives showed similar results.) Items on the comfort scale included "I find it easy to get emotionally close to others" and "I find it diffi- 
cult to depend on other people" (reversescored). The anxiety scale included items such as "I often worry that romantic partners won't want to stay with me" and "I often worry that romantic partners don't really love me." The comfort scale contained 10 items ( $\alpha=.87$; possible range from 10 to $50)$, and the anxiety scale contained 13 items ( $\alpha=.78$; possible range from 13 to 65 ).

\section{Caregiving style. Kunce and Shaver's} (1994) 32-item measure of caregiving was used, with items rated from $1=$ not at all like me, to $6=$ very much like me. The measure has four scales: proximity versus distance (e.g., "When my partner seems to want or need a hug, I'm glad to provide it"), sensitivity versus insensitivity ("I am very attentive to my partner's nonverbal signals for help and support"), cooperation versus control ("I tend to be too domineering when trying to help my partner"), and compulsive care ("I tend to get overinvolved in my partner's problems and difficulties"). All scales except compulsive care were moderately strongly correlated, for both sexes ( $r$ s ranged from .36 to .62). For this reason, two scales were formed, as in previous research (Feeney, 1996): compulsive care (as defined by Kunce \& Shaver, 1994), and responsive care (the sum of the remaining 24 items). The use of these scales was supported by the high reliability of the 24 item scale $(\alpha=.90)$, and by the fact that this reliability was reduced when the compulsive care items were included. Coefficient alpha for the compulsive care scale was .70 .

Attachment to spouse. Strength of attachment to the spouse was measured using a modified version of the WHOTO (Hazan \& Zeifman, 1994). In its original form, the 12 item WHOTO was designed to identify the various attachment figures used to meet needs for proximity-seeking, separation protest, secure base, and safe haven. The modified version replaced the original open-ended questions used by Hazan and Zeifman (1994) and Fraley and Davis (1997) with items of similar content, assessing the extent of reliance on the spouse as an attachment figure. For example, the item "Who is the person you most like to spend time with?" was reworded as, "The person I most like to spend time with is my spouse." Items were rated from 1 = strongly disagree, to $5=$ strongly agree.

Although the WHOTO was originally designed to measure four attachment needs or functions, the use of total scores as an index of attachment strength was supported by three findings: All correlations among the four functions exceeded .90; the full scale was highly reliable $(\alpha=.94)$; and factor analysis of the items revealed one factor that explained $90.3 \%$ of the variance, and on which all items loaded highly. The use of total scores is also consistent with Fraley and Davis's (1997) index of strength of attachment to a particular target, formed by combining responses to the open-ended questions.

Anticipated burden. The anticipated burden associated with caring for a dependent spouse was measured using a scale developed by Wells and Over (1994). Participants rated on 4 -point scales $(1=$ none, to $4=$ extreme) the burden they would feel if, in the future, their spouse were to experience each of 18 disabling conditions varying in severity (e.g., depression; severe stroke). Total scores on this scale were used $(\alpha=.95)$.

Willingness to care for spouse. Willingness to provide care for a dependent spouse was also measured using a scale developed by Wells and Over (1994). Participants were asked to consider the same 18 disabling conditions listed in the measure of burden, and to rate the extent to which they anticipated being willing to provide care for the spouse should each condition arise $(1=$ definitely not, to $4=$ definitely). Total scores were again used, with an alpha coefficient of .92. Previous research supports the reliability of this scale and its association with the measure of anticipated burden (Wells \& Over, 1994).

Semi-structured accounts. Participants were asked to think over their marriage to the 
time when they had most needed to give their spouse extra care and support. They were asked to state how the situation arose, how long the extra care was required, whether any other people had provided care, and, if so, who had provided the most care. They were then asked to describe the kinds of support they had given, how they had coped with the situation, how the situation had affected their relationship with their spouse, and how they felt now about the care they had provided. The accounts were obtained in written form. It is important to note that husbands and wives reported on different events, because each described a situation involving their own role as care provider. Hence, husbands' and wives' reports cannot be compared in terms of the "agreement" or reliability of the accounts.

A relatively small number of participants (42 husbands, 39 wives) did not provide a semi-structured account. Most of these participants explicitly stated that no particular need for extra care had arisen yet in their marriage; others simply did not complete the questions. Analyses showed that those who provided accounts did not differ from those who failed to do so, in terms of the attachment or caregiving dimensions of self or spouse.

Reports of how the situation arose were obtained for descriptive purposes only, and they were grouped into nine categories: spouse's accident, spouse's illness, change or loss of employment, other work stress, pregnancy and transition to parenthood, death in the family, other problems involving family members, financial difficulties, and other (including problems with housing). Reports of how long the extra care was required were recorded in days. The number of other care providers was recorded, together with the major care provider (self or other). Responses to the remaining questions were contentcoded, as detailed below. See Table 1 for examples.

Table 1. Coding of semi-structured reports of care

\begin{tabular}{ll}
\hline \hline Variable & Example \\
\hline $\begin{array}{l}\text { Type of Support Given } \\
\text { Tangible }\end{array}$ & $\begin{array}{l}\text { I gave him financial support. } \\
\text { I gave my partner lots of long, warm hugs. }\end{array}$ \\
$\begin{array}{l}\text { Both } \\
\text { I did all the chores; listened to her whenever she was down. } \\
\text { I decided to just leave him alone. }\end{array}$ \\
$\begin{array}{l}\text { Coping With Caregiving } \\
\text { Seeking social support }\end{array}$ \\
$\begin{array}{l}\text { Problem-focused } \\
\text { Positive reappraisal }\end{array}$ \\
$\begin{array}{l}\text { Escape-avoidance } \\
\text { I talked things over a lot with my family. } \\
\text { Effect on Relationship }\end{array}$ & I saw it as a way of bringing about a better future. \\
Brought partners closer & I often drank too much. \\
Created problems & It made our marriage much stronger and closer. \\
Had no marked effect & We gradually drifted further apart. \\
Feelings About Care & It didn't really affect our relationship at all. \\
Positive & \\
Negative & I gave the right sort of caring for the situation. \\
Mixed & I was intolerant of her pain and discomfort. \\
Emotional Tone of Report & Mostly OK; I could have been more sympathetic. \\
Negative or hostile & \\
Accepting & He never stopped moaning-what a tragedy queen! \\
\hline \hline
\end{tabular}


The type of support provided was coded as tangible (practical), emotional, both, or neither (a small number of respondents stated that they had simply left the spouse alone). Coping strategies were coded for the major themes present in the accounts, guided by the literature on coping. Four strategies were coded: support-seeking; problem-focused coping (learning new skills to deal with the situation); positive reappraisal (a form of emotion-focused coping); and escape-avoidance (a more maladaptive form of emotion-focused coping, involving reliance on alcohol or drugs). Because many respondents mentioned having used more than one coping strategy, each strategy was coded as a dichotomous variable $(1=$ mentioned; $0=$ not mentioned). Effect on the relationship was coded as either bringing the spouses closer, creating problems, or having no effect. Caregivers' current feelings about the care they provided were coded as positive, negative, or mixed. Finally, each account was scored for overall emotional tone, which was coded as a dichotomous variable $(0=$ accepting of the spouse's needs or behaviors; 1 = negative, hostile, or belittling in tone).

All coding was performed by an independent coder, and a second coder coded the responses from a subsample of 50 participants. Interrater reliability of the various codes (e.g., a particular coping strategy as mentioned or not mentioned; feelings about care as positive, negative, or mixed) was measured using Kappa coefficients, which assess the extent of agreement above that occurring by chance alone. All coefficients exceeded .82 .

\section{Procedure}

The order of the measures (attachment style; caregiving style; attachment to spouse; anticipated burden and willingness to care; semi-structured accounts) was counterbalanced using a Latin square design. Responses were anonymous, with code numbers used to enable matching of spouses' questionnaires. Students who were part of a couple eligible to participate in the study completed the measures in small groups, and they were trained in explaining the materials to their spouses. The spouses completed the measures at home, returning them to the researchers in a sealed envelope either by mail or through the student spouse. Students who were interested in the study but not eligible to participate attended small-group training sessions, designed to ensure that they could briefly explain to couples the purpose of the study and how to complete the materials. The students emphasized to the couples they recruited that the measures were to be completed independently, and the materials were again returned by mail or by the student contact. All participants completed an informed consent form that detailed the nature of their participation, and that provided them with methods of contacting the researchers or the ethical review board with any concerns about their participation.

\section{Results and Discussion}

The results of the study are presented in four sections. First, we provide descriptive data for the attachment and caregiving measures. Second, we present associations between attachment measures and semistructured accounts of caregiving experiences; these analyses extend previous research testing the proposition that attachment and caregiving are interrelated features of marital bonds. Next, we briefly describe relations between the caregiving scales and the semi-structured accounts; these analyses address the validity of the caregiving scales by linking them with reports of specific experiences of care. Finally, we address the relations among the questionnaire measures, focusing on the prediction of willingness to care for spouse (again, see Fig. 1). Throughout, the Type 1 error rate for bivariate correlations and standardized regression coefficients has been set at .01, to control for multiple comparisons. 


\section{Descriptive data}

The percentages endorsing the various attachment prototypes were: secure, $41 \%$; preoccupied, 19\%; dismissing, 23\%; and fearful, $17 \%$. These relative frequencies are similar to those reported from other samples (e.g., Feeney, 1996). The numbers of husbands and wives endorsing each prototype were secure (136 and 152, respectively), preoccupied (54 and 80), dismissing (107 and 60), and fearful (54 and 64). The sex difference in responses was reliable, $\chi^{2}$ (3) $=17.78, p<.001$, with men being more likely to endorse the dismissing prototype and less likely to endorse the preoccupied prototype. This result is also similar to that from previous samples (Feeney, 1996).

As would be expected from the partial overlap in item content, the categorical measure of attachment was strongly related to the attachment dimensions of comfort, $F$ $(3,694)=100.01$, and anxiety, $F(3,694)=$ $69.58 ; p<.001$ in each case. Secure and preoccupied groups reported higher comfort ( $M=26.41$ and 25.88 , respectively) than did fearful and dismissing groups ( $M$ $=21.25$ and 19.01 , respectively), and fearful and preoccupied groups reported higher anxiety ( $M=30.28$ and 29.54 , respectively) than dismissing and secure groups ( $M=$ 23.19 and 21.16, respectively). These group differences are in accordance with Bartholomew's (1990) theoretical formulation of the four attachment styles.

There was limited evidence of "partner matching" on measures of attachment and caregiving. Husbands' and wives' responses to the forced-choice attachment item were unrelated, $\chi^{2}(9)=9.77, n s$. (The largest attachment combination involved two secure spouses, $N=68$ couples; the smallest involved fearful husbands paired with dismissing wives, $N=9$.) Spouses' scores showed significant correlations for three of the four scales assessing attachment and caregiving styles: anxiety $(r=.29)$, responsive care $(r=.30)$, and compulsive care $(r=$ $.23), p<.01$ in each case. (Correlations between attachment and caregiving scales are presented later in Table 2.)

\section{Attachment and semi-structured accounts of caregiving}

The numbers of husbands and wives describing the various kinds of caregiving situations were as follows: spouse's accident ( 24,36 , respectively throughout), spouse's illness $(84,93)$, change or loss of employment $(6,45)$, other work stress $(27,58)$, pregnancy and transition to parenthood $(73,2)$, death in the family $(56,36)$, other family problems $(15,11)$, financial difficulties $(6,10)$, and other $(30,27)$. Note that some situations were mentioned more frequently by husbands or by wives, because of the gender-linked nature of the situation: Situations related to pregnancy were mentioned by more husbands than wives, whereas situations involving spouse's employment were mentioned by more wives than husbands.

Care requirements. Three of the semistructured questions (length of time that care was needed, number of care providers, major provider of care) were included as control variables, to check whether attachment measures were related to the demands of the caregiving situation. Attachment security was unrelated to the control variables, as shown by correlational analyses (using the attachment dimensions) and discriminant analyses (using the forcedchoice attachment measure). Further, although participants were not required to specify exactly when the situation occurred, $28.2 \%$ reported that it was current or ongoing; attachment dimensions were unrelated to such reports. In summary, any links between attachment and reports of care are unlikely to reflect systematic differences in the demands of the situation.

By contrast, as detailed below, attachment was related to reports of the type of support given, coping strategies, effect on the relationship, current feelings about care, and to the emotional tone of the accounts (although some findings were gender-specific). These relations were assessed in two ways. First, discriminant analyses were conducted in which the coded re- 
sponses to the particular question formed the grouping variable, and the discriminating variables were the attachment dimensions (own and partner's comfort and anxiety). ${ }^{1}$ This approach allows the attachment characteristics of both partners to be readily incorporated, and it provides a parallel with the quantitative component of the study (in which own and partner's attachment dimensions were used in structural equation modeling). Second, more finegrained information about the effects of particular attachment styles was obtained by frequency comparisons relating own (forced-choice) attachment style to the reports of caregiving.

Type of support given. Attachment dimensions were related to the type of support given by husbands $\left(\chi^{2}(4)=12.62, p<.02\right)$, and wives $\left(\chi^{2}(6)=14.17, p<.05\right)$. $^{2}$ Husbands who reported providing both tangible and emotional support were similar to other husbands in terms of own attachment dimensions, but their wives were lower in anxiety $(M=27.77)$ than other wives $(M=$ 31.28). Similarly, wives who reported giving both tangible and emotional support did not differ from other wives in terms of own attachment, but their husbands were higher

1. In these analyses, interaction terms between own comfort and anxiety were also included. The interaction between husbands' comfort and anxiety was unrelated to all dependent variables. Wives' attachment dimensions showed interactive effects on type of support given by husbands (wives low in comfort and anxiety were least likely to receive both tangible and emotional support), and on wives' coping strategies (wives high in comfort and low in anxiety reported more problem-focused coping, whereas those low in comfort and high in anxiety reported more escape-avoidance).

2. For all discriminant analyses reported in this article, the chi-square test assesses the significance of Wilks's Lambda, or the overall association between the grouping variable (semi-structured accounts of care), and the dimensions being tested (either attachment or caregiving). The degrees of freedom for these tests vary from one analysis to another because in some analyses, one or two predictor variables did not meet the criteria for inclusion (in terms of $F$ to enter). In all discriminant analyses, only a single discriminant function was obtained. in comfort $(M=29.95)$ than other husbands $(M=27.21)$.

Forced-choice attachment style was related to type of support for wives only, $\chi^{2}$ (9) $=22.37, p<.01$. This result stemmed from the difference in responses between dismissing wives and other wives. All seven reports of simply "leaving the spouse alone" came from dismissing wives; further, "complete" support (tangible and emotional) was reported by $36 \%$ of wives overall, but by only $19 \%$ of dismissing wives.

Together, these findings support the hypothesized link between secure attachment and provision of more complete support. Dismissing wives, in particular, were less likely to offer both tangible and emotional support. Partner's attachment was also relevant, with the results suggesting that wives who are low in relationship anxiety and husbands who are high in comfort with closeness elicit more effective care and support from their spouses. This effect is likely to stem from the behavior of the spouse needing care, whose positive expectations of attachment figures may facilitate more open and honest communication of needs. This explanation fits with previous studies linking men's comfort and women's lack of anxiety to more effective communication (Collins \& Read, 1990; Feeney, Noller, \& Callan, 1994).

Problem-focused coping. The discriminant analysis for problem-focused coping was significant for wives' reports only, $\chi^{2}(1)=$ $9.57, p<.005$. Wives who reported using this strategy were lower in anxiety $(M=$ 20.91) than those who did not $(M=30.07)$.

The link with attachment style was significant for both husbands and wives, $\chi^{2}(3)$ $=8.64$ and 8.00 , respectively, $p<.05$ in each case. Problem-focused coping was reported by $16 \%$ of the sample overall; however, whereas $30 \%$ of secure husbands and $26 \%$ of secure wives mentioned this strategy, it was reported by only one fearful husband and by no fearful or dismissing wives.

Support-seeking. Links between attachment variables and carers' reports of sup- 
port-seeking were obtained for both sexes. For husbands, the discriminant analysis was marginally significant $\left(\chi^{2}(4)=8.34, p<\right.$ .08 ), but showed a significant univariate $F$ test for own comfort with closeness: Husbands who reported seeking support were higher in comfort $(M=30.21)$ than were those who did not $(M=28.43)$.

For wives, forced-choice attachment style was related to support-seeking, $\chi^{2}(3)$ $=9.86, p<.05$. This result reflected the low levels of support-seeking among dismissing wives: This coping strategy was reported by $23 \%$ of wives overall, but by only $8 \%$ of dismissing wives.

Positive reappraisal. Reports of positive reappraisal were unrelated to attachment dimensions and attachment styles.

Escape-avoidance. Reports of escapeavoidance were unrelated to forced-choice attachment, but wives' reports of this coping strategy were related to attachment dimensions, $\chi^{2}(2)=6.18, p<.05$. Specifically, wives who reported using escape-avoidance were much higher in anxiety $(M=$ $38.33)$ than were other wives $(M=29.60)$.

Coping strategies: Summary. Positive reappraisal was the only coping strategy that was unrelated to the attachment measures. This result may reflect the fact that positive reappraisal is likely to vary markedly in terms of its efficacy, depending on the situation and on whether other (more active) coping strategies are also employed. It should also be noted that all reliable links between attachment measures and reported coping strategies applied to own (rather than partner's) attachment.

For husbands, comfort with closeness was associated with support-seeking; furthermore, dismissing wives were unlikely to report having engaged in support-seeking. These results are in accordance with $\mathrm{Hy}$ potheses 1 and 3; they also fit with previous findings from studies of affect regulation, linking secure attachment with preparedness to acknowledge distress and seek sup- port from others (Feeney, 1998; Mikulincer \& Florian, 1998).

Own anxiety was related negatively to wives' use of problem-focused coping (i.e., learning new skills as carers), and positively to wives' use of escape-avoidance. Further, fearful husbands and wives and dismissing wives were unlikely to report using problem-focused coping. These results support the hypothesis that less adaptive coping patterns tend to be adopted by those who are insecure about their relationships, especially when insecurity is manifested as anxiety over loss and abandonment. Similarly, other studies have linked relationship anxiety with substance use and other maladaptive forms of emotion-focused coping (Feeney et al., 2000; Mikulincer \& Florian, 1998).

Effect on the relationships. Results for this variable were similar for both sexes. Attachment dimensions were related to perceived effect of caregiving, $\chi^{2}(6)=23.43$ for husbands and 21.72 for wives, $p<.005$ in each case. Husbands who saw the situation as bringing the spouses closer were higher in comfort $(M=29.87)$ than were other husbands $(M=26.63)$, and those who reported that it created problems had wives who were higher in anxiety $(M=34.86)$. than were other wives $(M=29.47)$. Similarly, wives reporting increased closeness were higher in comfort $(M=31.18)$ than were other wives $(M=28.58)$; those reporting problems had husbands who were higher in anxiety $(M=33.56)$ than were other husbands $(M=29.43)$.

Attachment style was also related to perceived effect on the relationship, $\chi^{2}(6)=$ 15.96 for husbands and 16.51 for wives, $p<$ .05 . These results were primarily attributable to the pattern of responses of fearful participants. Overall, only $11 \%$ of the sample reported that the situation had created problems; however, such problems were reported by $20 \%$ of fearful husbands and $22 \%$ of fearful wives.

Thus, as expected, spouses who were high in comfort with closeness tended to see caregiving as bringing the couple closer. 
Those who are comfortable with intimacy emphasize the importance of open communication (Feeney \& Noller, 1991). They are also likely to renegotiate their relationship actively in the face of a crisis, such as periods of physical separation (Feeney, 1998). The increased closeness that these individuals report following caregiving probably reflects their active engagement in any problems that arise. In addition, the spouses of husbands and wives who were high in anxiety tended to see the situation as creating problems. This finding suggests that relationship anxiety in the care-receiver exacerbates the stress associated with spousal caregiving.

Carers' feelings about their care. Links between attachment measures and reported feelings about care provided to the spouse were confined to wives' reports. The significant discriminant analysis $\left(\chi^{2}(2)=7.93, p<\right.$ $.05)$ showed that wives who reported feeling negative about their care were lower in comfort $(M=28.06)$ than were other wives $(M$ $=30.32$ ), and their husbands were higher in anxiety $(M=34.80)$ than were other husbands $(M=29.53)$. Attachment style was also related to wives' feelings about care provided, $\chi^{2}(6)=12.62, p<.05$ : Negative feelings were reported by only $10 \%$ of wives overall, but by $35 \%$ of preoccupied wives.

The fact that the hypothesized link between attachment and satisfaction with own caregiving was restricted to wives may reflect gender roles. Women are socialized to be caretakers and nurturers (Surra \& Longstreth, 1990), and hence the quality of own caregiving may be more salient to them. The obseved link is likely to reflect differences in both behavior and perceptions. As we will see later, wives high in comfort with closeness report a more constructive style of spousal caregiving in everyday life, and this style is likely to be evident in specific times of need. In addition, however, wives high in comfort are more strongly fixed in their sense of self-worth (Bartholomew, 1990), and hence may be less critical of their own efforts in this area. The "partner" effect for feelings about care may result from anxious husbands being more demanding and dependent in times of need. The demands of such husbands are less likely to appear to be adequately met.

Emotional tone. As expected, the emotional tone of the accounts was linked to attachment dimensions for both husbands $\left(\chi^{2}(3)=11.85, p<.01\right)$, and wives $\left(\chi^{2}(2)=\right.$ $9.68, p<.01)$. Husbands who described their wives' needs or behaviors in negative terms were higher in anxiety $(M=35.75)$ than were other husbands ( $M=29.83)$, and their wives were higher in anxiety $(M=34.35)$ than were other wives $(M=29.47)$. Wives who described their husbands in negative terms were higher in anxiety than were other wives $(M \mathrm{~s}=32.36$ and 29.35), and also lower in comfort ( $M \mathrm{~s}=28.40$ and 30.59$)$.

Emotional tone was also linked to attachment style: for husbands, $\chi^{2}(3)=9.12$, $p<.05$; for wives, $\chi^{2}(3)=18.65, p<.0005$. Negative emotional tone was present in only $6 \%$ of husbands' accounts overall, but in $15 \%$ of the accounts from fearful husbands. Moreover, negative emotional tone was present in only $12 \%$ of wives' accounts overall, but in $25 \%$ of the accounts from dismissing wives.

These findings support Hypothesis 3, and they are of crucial importance to this study. They show that attachment security is manifest not only in spouses' self-reports of their caregiving and care-receiving roles, but also in the tone of their discourse, as rated by independent judges. Thus, the findings linking attachment measures with accounts of caregiving cannot be dismissed as due simply to global response bias or common-method variance. The negative tone observed in the accounts of highly anxious spouses may also be evident in actual caregiving interactions, where it is likely to have highly negative consequences both for the immediate situation and for relationship maintenance.

\section{Caregiving style and semi-structured accounts of caregiving}

Discriminant analyses were also used to relate own and partner's caregiving scales (re- 
sponsive care, compulsive care) to semistructured accounts of caregiving. As noted earlier, these analyses help to establish the validity of the caregiving scales. Because these analyses serve a validational role, rather than being of focal interest, they were restricted to major caregiving variables: type of support given, perceived effect on the relationship, and carers' feelings about their care.

Type of support given. Reports of the type of support given were related to caregiving scales: $\chi^{2}(6)=12.36, p<.05$ for husbands; $\chi^{2}(4)=11.39, p<.05$ for wives. In each case, the significant discriminating variables were own and partner's responsive care. Husbands who reported giving only tangible support were lower in responsive care $(M=98.73)$ than were other husbands $(M$ $=105.19)$, and their wives were lower in responsive care $(M=107.76)$ than were other wives $(M=112.11)$. Similarly, wives who gave only tangible support were lower in responsive care $(M=107.97)$ than were other wives $(M=113.54)$, and their husbands were lower in responsive care ( $M=$ 99.55) than were other husbands ( $M=$ 106.77).

Effect on the relationship. Perceived effects of caregiving were strongly linked to caregiving scales for both husbands, $\chi^{2}(4)=$ $20.88, p<.0001$, and wives, $\chi^{2}(6)=20.14, p$ $<.005$. For husbands, own responsive care was the only discriminating variable: Husbands reporting relationship problems were much lower in responsive care than were other husbands ( $M \mathrm{~s}=86.76$ and 104.52). Compared with wives who reported increased closeness, those reporting problems were lower in responsive care of both self $(M \mathrm{~s}=103.20$ and 112.65$)$ and $\operatorname{partner}(M \mathrm{~s}=$ 95.26 and 104.82).

Carers' feelings about their care. Current feelings about care were also related to caregiving scales for husbands, $\chi^{2}(6)=$ 13.57, $p<.05$, and wives, $\chi^{2}(4)=25.09, p$ $<.0001$. Own responsive care was the only discriminating variable: Husbands and wives who reported negative feelings were lower in responsive care $(M=98.70$ and 98.19 , respectively) than were those reporting positive feelings $(M=105.06$ and 113.15).

\section{Summary of findings from semi-structured accounts}

In summary, variables coded from the semistructured accounts were linked to the measure of responsive care. Participants who reported a general caregiving style marked by high responsiveness also described specific events in which they responded to their spouse's diverse needs, and which led to greater couple intimacy and to positive feelings about the care provided. These links between structured and semi-structured reports are important, because they suggest that the responsive care scale has some validity as a measure of an individual's ability to identify and respond to a partner's needs. (Given that responsive care involves providing closeness and comfort, high scores on this scale should be linked with more effective caregiving.) The content-coded variables were not linked to the compulsive care scale, but this result is not surprising. Compulsive care involves the tendency to neglect one's own needs when giving care. This tendency is likely to prove problematic and burdensome to the caregiver, but it need not negate the provision of adequate care, especially in the short term.

The results reported thus far suggest that "complete" support of the spouse (tangible and emotional) is more likely to occur when the caregiver is high in responsive care, and the receiver of care is securely attached. Both secure attachment and responsive care also appear to have implications for the carer's feelings about the quality of the care, and for the effect of caregiving on the couple bond. These results highlight the potential role of attachment and caregiving styles as predictors of willingness to care for a dependent spouse. 


\section{Predicting willingness to care}

Bivariate correlations among the variables in Figure 1 are shown in Table 2. As expected, reliable associations existed among the attachment and caregiving scales. Responsive care was related positively to comfort with closeness and negatively to relationship anxiety, for both sexes. Compulsive care was related positively to anxiety, but was not related to comfort. These results replicate those reported by Feeney (1996), except for the association between comfort and compulsive care; in that study, this association was negative (and significant) for both husbands and wives. The modest size of the associations obtained in the present study indicates that attachment and caregiving are empirically distinguishable constructs. Further, correlations between the attachment dimensions and the measure of strength of attachment to spouse were in the order of .20 to .25 , indicating that attachment style and attachment strength are also nonredundant constructs.

Predictors of willingness to care for a dependent spouse were investigated by structural equation modeling, using EQS (Bentler, 1993), with the maximum likelihood method of estimation. The analyses were conducted separately for the prediction of husbands' and wives' scores. The first step in analyzing the structural relations was to compare the proposed theoretical model (conceptualizing attachment strength as influenced by styles of attachment and caregiving) with the alternative model (conceptualizing attachment strength as a predictor of caregiving style). The proposed model was tested as illustrated in Figure 1. That is, although no specific predictions were made as to whether attachment and caregiving styles would have direct or indirect effects on willingness to care, direct paths were not included in the initial data analysis.

The initial proposed model provided a relatively good fit to the data, as indicated by three criteria: Akaike's information criterion (AIC); the ratio of the model chisquare $\left(\chi^{2}\right)$ statistic to the degrees of freedom (for both these criteria, low values are optimal); and the comparative fit index (CFI, which should approach .9). The values of these statistics were as follows: for husbands, $\mathrm{AIC}=23.46, \chi^{2}(23)=69.46, p<$ $.001, \mathrm{CFI}=.92$; for wives, $\mathrm{AIC}=20.60, \chi^{2}$ $(23)=66.60, p<.001, \mathrm{CFI}=.91$. The alternative model differed from the proposed model only in terms of the role of attachment strength, which was placed alongside attachment style as a predictor of caregiving style. This model provided a poor fit to the data: for husbands, $\mathrm{AIC}=142.97, \chi^{2}$ $(22)=186.97, p=.001, \mathrm{CFI}=.72$; for wives,

Table 2. Correlations among questionnaire measures

\begin{tabular}{lccccccc}
\hline \hline & 1 & 2 & 3 & 4 & 5 & 6 & 7 \\
\hline 1 Comfort & -.04 & - & & & & \\
2 Anxiety & -.04 & & & & & \\
3 Strength of attachment & $-.086^{* *}$ & $-.22^{*}$ & - & & & \\
& $.21^{*}$ & $-.24^{*}$ & & & & \\
4 Responsive care & $.25^{*}$ & $-.26^{* *}$ & $.51^{* *}$ & - & & \\
& $.25^{*}$ & $-.42^{* *}$ & $.50^{* *}$ & & & \\
5 Compulsive care & .10 & $.29^{* *}$ & .06 & -.09 & - & \\
& $.16^{*}$ & $.18^{*}$ & .09 & -.06 & & & \\
6 Burden & -.01 & .07 & $-.26^{* *}$ & $-.33^{* *}$ & -.01 & - & \\
& -.04 & .09 & $-.28^{* *}$ & $-.25^{*}$ & -.01 & & \\
7 Willingness to care & .05 & -.01 & $.39^{* *}$ & $.29^{* *}$ & .10 & $-.55^{* *}$ & - \\
& $.19^{*}$ & -.06 & $.37^{* *}$ & $.28^{* *}$ & .09 & $-.55^{* *}$ & \\
\hline \hline
\end{tabular}

Note. In each cell, the top entry is for husbands; the bottom entry is for wives.

${ }^{*} p<.01 .{ }^{* *} p<.001$. 
$\mathrm{AIC}=155.53, \chi^{2}(22)=199.53, p<.001$, $\mathrm{CFI}=.71$. In summary, initial model testing clearly supported the proposed theoretical model, which was hence investigated further.

In testing models with many variables, it is not unusual to find that the fit of a proposed model can be improved by adding or removing certain paths (Newcomb \& Bentler, 1988). This information is provided by the Lagrange multiplier test (in the case of additional associations that improve the fit of the model), and the Wald test (in the case of hypothesized associations that reduce the fit). In the present case, these test statistics were used to provide minor revisions to the proposed model.

Additional paths were included only if they resulted in a significant improvement to fit, and if they made theoretical sense. Using these criteria, a direct path was added from own comfort to husbands' attachment strength, and from own comfort to wives' willingness to care. Paths that did not attain statistical significance were deleted from the model. For both sexes, for example, the compulsive care scale was unrelated to burden, attachment strength, and willingness to care, and hence was deleted from the model. In addition, for husbands, attachment strength was unrelated to anticipated burden.

The final structural models for husbands and wives are shown in Figures 2 and 3, respectively. These models provided an adequate fit to the model: for husbands, $\mathrm{AIC}=5.50, \chi^{2}(25)=55.50, p<.001, \mathrm{CFI}$ $=.95$; for wives, AIC $=5.73, \chi^{2}(25)=$ $57.73, p<.001, \mathrm{CFI}=.95$. The adequacy of fit is further indicated by the small values of the mean standardized residuals (.051 for husbands; .054 for wives).

In many respects, the models were similar for husbands and wives. First, in terms of direct effects, the strongest single effect was of anticipated burden ( -.49 for both husbands and wives). This finding supports $\mathrm{Hy}$ pothesis 6 , and is consistent with a large body of research pointing to the negative consequences of caregiver burden (e.g., Miller et al., 1991; Orbell et al., 1993). For each gender, there were also direct effects of strength of attachment to spouse (.28 and .21). In further support of Hypothesis 6, this result points to strength of attachment as a useful predictor of willingness to care. The only difference in terms of direct effects was that for wives only, willingness to care was predicted by own comfort with closeness.

Some indirect effects were also similar for husbands and wives. For each gender, own responsive care was associated with willingness to care, through lower anticipated burden. In addition, both own and spouse's responsive care were indirectly associated with willingness to care, through attachment strength. These results support Hypothesis 5. As expected (Hypotheses 4 and 5), both own and partner's attachment dimensions showed indirect effects through their links with caregiving dimensions. In addition, husbands' comfort had an indirect effect through attachment strength. These results point to attachment and caregiving styles as useful predictors of willingness to care for spouse.

Overall, the results provide considerable support for the proposed model of caregiving. They suggest that attachment and caregiving behaviors are interrelated features of marital bonds, and that both attachment style and attachment strength help to explain individual differences in willingness to care. The strongest effects of attachmentrelated variables were for attachment strength (both genders), and wives' comfort, which predicted own willingness to care directly, and indirectly through wives' responsive care.

\section{General Discussion and Conclusions}

Before discussing the results in more detail, it is important to consider the strengths and limitations of this research. The sample was relatively large and representative, and previous studies support the reliability of the data collection methods (i.e., using students to participate directly, and to recruit others; Noller, Law, \& Comrey, 1987). The semistructured reports were mainly retrospec- 


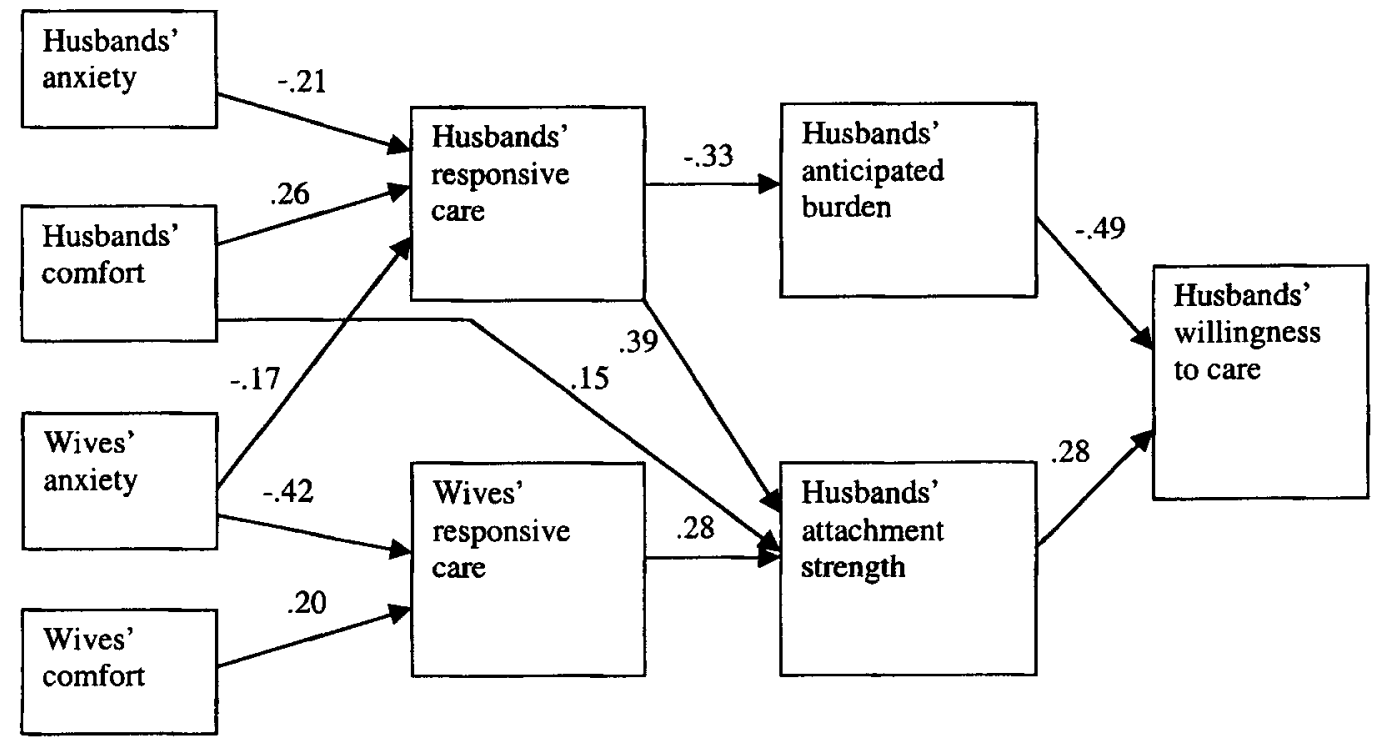

Figure 2. Final structural model for prediction of husbands' willingess to provide care.

tive, except for measures of emotional tone and feelings about care; however, many respondents described ongoing events. We would argue that questions about spouses' time of greatest need should be salient to all couples, but we acknowledge that recall may be more accurate for those describing recent events. Some questionnaire items required participants to imagine situations involving various kinds of spousal disability, and to rate their reactions. This method also has limitations, as some people may find it

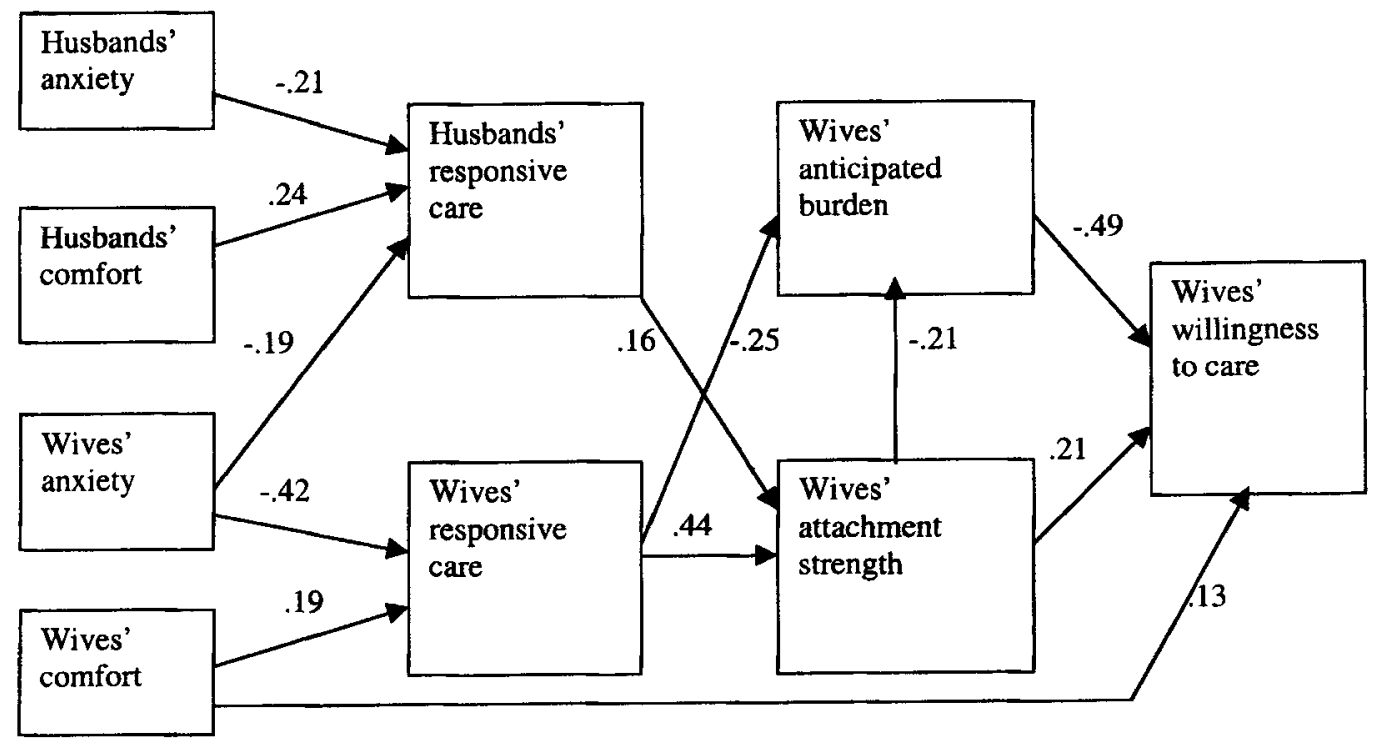

Figure 3. Final structural model for prediction of wives' willingess to provide care. 
difficult to assess their reactions or to report them honestly. However, the methods used here complement each other, and both methods suggest that studies of caregiving should benefit from the inclusion of attachment-related variables. Longitudinal designs are needed to further test the proposed causal relations, especially given that measures of attachment style are somewhat unstable over time. Future research would also benefit from asking both spouses to report on the same caregiving events, so that similarities and differences in their perceptions could be assessed.

The present results suggest that both attachment styles and attachment dimensions provide important information about individual differences in spousal caregiving. In terms of attachment styles, preoccupied wives reported more negative feelings about the care they provided; this finding may reflect a genuine failure to meet the partner's needs, or a tendency to apply unrealistic (or "compulsive") standards when evaluating their own caregiving (Kunce \& Shaver, 1994). Fearful spouses (both husbands and wives) were unlikely to report using problem-focused coping, and likely to state that caregiving had led to ongoing relationship problems; in addition, fearful husbands tended to use a negative or belittling tone in describing their wives' needs for care. These findings linking fearful attachment with negative patterns of caregiving are consistent with previous research (Feeney, 1996).

However, in the present study, the results for dismissing wives were particularly striking. Dismissing wives were unlikely to provide complete care (sometimes taking no action at all to help the spouse), unlikely to adopt constructive coping methods (support-seeking or problem-focused coping), and likely to use a negative or belittling tone in describing their husbands' needs for care. Given that dismissing attachment involves a preference for interpersonal distance and a denial of attachment needs, it is not surprising that dismissing individuals find the role of care-provider difficult. The gender-specific nature of the results may be explained in terms of sex-role socialization. Women are traditionally encouraged and expected to adopt affiliative and nurturing roles (Kunkel \& Burleson, 1998). These expectations may make it particularly difficult for dismissing women to deal with caregiving. Together with previous research, the present results are important in suggesting that the situations in which dismissing attachment becomes potentially problematic may differ for men and women. That is, dismissing attachment may be linked most strongly to ongoing issues concerning distance regulation for men (Feeney, 1999), but to issues concerning caregiving for women.

In terms of attachment dimensions, own comfort with closeness was associated with support-seeking (husbands), acceptance of the spouse's needs, and satisfaction with care provided (wives), perceptions of positive effects on the marriage (both genders), and higher levels of responsive care (both genders). These findings can be understood in terms of the caregiving process, in which one partner's expression of needs and feelings and the other partner's accepting attitudes foster increased intimacy. In contrast, own anxiety over relationships was related to less problem-focused coping and more escape-avoidance (wives), less acceptance of the spouse's needs (both genders), and lower levels of responsive care (both genders). These results reflect the attitudes and behaviors embodied in working models of attachment (Collins \& Read, 1994). That is, for spouses who are called on to provide care, relationship anxiety seems to be linked with caregiving that is somewhat self-centered, marked by difficulty in setting aside one's own relational needs and responding to those of the partner. Previous research also suggests that those high in relationship anxiety perceive themselves as unappreciated by other people (Hazan \& Shaver, 1990), which may make it difficult to cope constructively with caregiving.

Although own attachment dimensions were of prime importance for some aspects of caregiving (especially coping), partner attachment dimensions also need to be con- 
sidered. Partners' comfort was associated only with the greater likelihood of wives providing complete care. However, husbands' anxiety was associated with wives' dissatisfaction with own care, and wives' perceptions of ongoing problems related to caregiving. Further, wives' anxiety was associated with husbands' failing to provide complete care, perceiving ongoing problems, using negative tone to describe wives' needs, and reporting lower levels of responsive care. The negative effects of partners' relationship anxiety warrant further research. For spouses requiring care, such anxiety is likely to involve considerable concern about whether the partner will "be there" for them, and this concern may be manifested in highly dependent or demanding behaviors. Overall, the effects of partner attachment highlight the need to study adult attachment and caregiving as dyadic processes, rather than at the level of the individual.

In conclusion, this research suggests that insecure attachment and low levels of responsive care are linked to lower quality of past (or ongoing) care, and also to less willingness to provide care in the future.

\section{References}

Ainsworth, M. D. S. (1989). Attachments beyond infancy. American Psychologist, 44, 709-716.

Bartholomew, K. (1990). Avoidance of intimacy: An attachment perspective. Journal of Social and Personal Relationships, 7, 147-178.

Bartholomew, K., \& Horowitz, L. M. (1991). Attachment styles among young adults: A test of a fourcategory model. Journal of Personality and Social Psychology, 61, 226-244.

Bentler, P. M. (1993). EQS: A structural equations program manual. Los Angeles: BMDP Statistical Software.

Bowlby, J. (1969). Attachment and loss: Vol.1. Attachment. New York: Basic Books.

Bowlby, J. (1973). Attachment and loss: Vol.2. Separation: Anxiety and anger. New York: Basic Books.

Bowlby, J. (1980). Attachment and loss: Vol.3. Loss. New York: Basic Books.

Brody, E. M. (1985). Parent care as a normative family stress. The Gerontologist, 25, 19-29.

Carnelley, K. B., Pietromonaco, P. R., \& Jaffe, K. (1996). Attachment, caregiving, and relationship functioning in couples: Effects of self and partner. Personal Relationships, 3, 257-277.

Cicirelli, V. G. (1993). Attachment and obligation as daughters' motives for caregiving behavior and
These findings have implications for decisions concerning informal versus institutional care: Clearly, individuals differ in their willingness to care for a dependent spouse, and those whose attachment and caregiving styles result in caregiving being seen as burdensome and unsatisfying are less likely to adopt or persist in this role. The results also have implications for the well-being of carer and receiver of care in the event of spousal care. Dependent spouses who are highly anxious and insecure about their relationships may be reluctant to express their needs for fear of alienating their partners; however, this failure to express needs is likely to make the caregiving task more difficult. In terms of carers, a spouse who is comfortable with intimacy and sensitive to others' needs may see caregiving as a means of enhancing intimacy, whereas one who is highly anxious may respond to the dependent partner with overt or covert hostility. Professionals who work with support groups or with individual carers and care-receivers should find it helpful to consider the impact of individual differences in attachment and caregiving styles.

subsequent effect on subjective burden. Psychology and Aging, 8, 144-155.

Cicirelli, V. G. (1995). A measure of caregiving daughters' attachment to elderly mothers. Journal of Family Psychology, 9, 89-94.

Collins, N. L., \& Read, S. J. (1990). Adult attachment, working models, and relationship quality in dating couples. Journal of Personality and Social Psychology, 58, 644-663.

Collins, N. L., \& Read, S. J. (1994). Cognitive representations of attachment: The structure and function of working models. In K. Bartholomew \& D. Perlman (Eds.), Advances in personal relationships: Vol. 5. Attachment processes in adulthood (pp. 53-90). London: Jessica Kingsley.

Feeney, J. A. (1995). Adult attachment and emotional control. Personal Relationships, 2, 143-159.

Feeney, J. A. (1996). Attachment, caregiving and marital satisfaction. Personal Relationships, 4, 401-416.

Feeney, J. A. (1998). Adult attachment and relationship-centered anxiety: Responses to physical and emotional distancing. In J. A. Simpson \& W. S. Rholes (Eds.), Attachment theory and close relationships (pp. 189-218). New York: Guilford Press.

Feeney, J. A. (1999). Issues of closeness and distance in dating relationships: Effects of sex and attachment 
style. Journal of Social and Personal Relationships, $16,571-590$

Feeney, J. A., \& Noller, P. (1991). Attachment style and verbal descriptions of romantic partners. Joumal of Social and Personal Relationships, 8, 187-215.

Feeney, J. A., \& Noller, P. (1996). Adult attachment. Thousand Oaks, CA: Sage.

Feeney, J. A., Noller, P., \& Callan, V. J. (1994). Attachment style, communication and satisfaction in the early years of marriage. In K. Bartholomew \& D. Perlman (Eds.), Advances in personal relationships: Vol. 5. Attachment processes in adulthood (pp. 269-308). London: Jessica Kingsley.

Feeney, J. A., Noller, P., \& Roberts, N. (2000). Attachment and close relationships. In C. Hendrick \& S. S. Hendrick (Eds.), Close relationships: A sourcebook (pp. 185-201). Thousand Oaks, CA: Sage.

Fraley, R. C., \& Davis, K. E. (1997). Attachment formation and transfer in young adults' close friendships and romantic relationships. Personal Relationships, $4,131-144$.

Fredriksen, K. I. (1996). Informal caregiving: Current trends in public policy and service provision. Journal of Clinical Geropsychology, 2, 37-50.

Griffin, D. W., \& Bartholomew, K. (1994). The metaphysics of measurement: The case of adult attach ment. In K. Bartholomew \& D. Perlman (Eds.), Advances in personal relationships: Vol. 5. Attach. ment processes in adulthood (pp. 17-52). London: Jessica Kingsley.

Hazan, C., \& Shaver, P. R. (1987). Romantic love conceptualized as an attachment process. Journal of Personality and Social Psychology, 52, 511-524.

Hazan, C., \& Shaver, P. R. (1990). Love and work: An attachment-theoretical perspective. Journal of Personality and Social Psychology, 59, 270-280.

Hazan, C., \& Zeifman, D. (1994). Sex and the psychological tether. In K. Bartholomew \& D. Perlman (Eds.), Advances in personal relationships: Vol. 5. Attachment processes in adulthood (pp. 151-178). London: Jessica Kingsley.

Kunce, L.J., \& Shaver, P.R. (1994). An attachmenttheoretical approach to caregiving in romantic relationships. In K. Bartholomew \& D. Perlman (Eds.), Advances in personal relationships: Vol. 5. Attachment processes in adulthood (pp. 205-237). London: Jessica Kingsley.

Kunkel, A. W., \& Burleson, B. R. (1998). Social support and the emotional lives of men and women: An assessment of the different cultures perspective. In D. J. Canary \& K. Dindia (Eds.), Sex differences and similarities in communication (pp. 101-125). Mahwah, NJ: Erlbaum.

Marks, N. F. (1998). Caregiving across the lifespan: National prevalence and predictors. Family Relations:
Journal of Applied Family and Child Studies, 45, 27-36.

McFall, S., \& Miller, B. H. (1992). Caregiver burden and nursing home admission of frail elderly persons. Journal of Gerontology: Social Sciences, 47, S73-79.

Mikulincer, M., \& Florian, V. (1998). The relationship between adult attachment styles and emotional and cognitive reactions to stressful events. In J. A. Simpson \& W. S. Rholes (Eds.), Attachment theory and close relationships (pp. 143-165). New York: Guilford Press.

Miller, B., McFall, S., \& Montgomery, A. (1991). The impact of elder health, caregiver involvement, and global stress on two dimensions of caregiver burden. Journal of Gerontology: Social Sciences, 46, S9-19.

Mui, A. C. (1995). Perceived health and functional status among spouse caregivers of frail older persons. Journal of Aging and Health, 7, 283-300.

Newcomb, M., \& Bentler, P. M. (1988). Impact of adolescent drug use and social support on problems of young adults: A longitudinal study. Journal of $A b$ normal Psychology, 97, 64-75.

Noller, P., Law, H., \& Comrey, A. L. (1987). Cattell, Comrey, and Eysenck personality factors compared: More evidence for the five robust factors? Journal of Personality and Social Psychology, 53, 775-782.

Orbell, S., Hopkins, N., \& Gillies, B. (1993). Measuring the impact of informal caring. Journal of Community and Applied Social Psychology, 3, 149-163.

Shaver, P. R., \& Hazan, C. (1988). A biased overview of the study of love. Journal of Social and Personal Relationships, 5, 473-501.

Shaver, P. R., Hazan, C., \& Bradshaw, D. (1988). Love as attachment: The integration of three behavioral systems. In R. J. Sternberg \& M. Barnes (Eds.), The psychology of love (pp. 68-99). New Haven, CT: Yale University Press.

Stone, R., Cafferata, G. L., \& Sangl, J. (1987). Caregivers of the frail elderly: A national profile. The Gerontologist, 27, 616-626.

Surra, C. A., \& Longstreth, M. (1990). Similarity of outcomes, interdependence, and conflict in dating relationships. Journal of Personality and Social Psychology, 59, 501-516.

Weiss, R. S. (1991). The attachment bond in childhood and adulthood. In C. M. Parkes, J. StevensonHinde, \& P. Marris (Eds.), Attachment across the life cycle (pp. 66-76). London: Tavistock/Routledge.

Wells, Y., \& Over, R. (1994). Willingness to provide spousal care if needed in the future. Australian Journal of Marriage and Family, 15, 76-85. 